\section{Diversidade Humana e Suas}

\section{Complexidades: Um Olhar Sobre as} Identidades dos Surdos da Comunidade de Viçosa-MG

Human Diversity and Its Complexities: A Look at the Identities of the Deaf of the Viçosa-MG Community

Fúlvia Ventura Leandro*, Michelle Nave Valadão**, Rita de Cássia Pereira Farias ${ }^{* * *}$

RESUMO: O presente artigo trata de uma reflexão sobre as identidades do sujeito surdo, verificando aspectos ligados à negação ou aceitação da surdez e da Língua Brasileira de Sinais (Libras). O público pesquisado foi composto por quatro surdos adultos participantes de um projeto de extensão na Universidade Federal de Viçosa, Minas Gerais. A abordagem metodológica foi qualitativa, embasada em um estudo de caso, cuja coleta de dados se deu a partir de entrevistas semiestruturadas. $\mathrm{O}$ processo investigativo revelou que os participantes da pesquisa passaram por processos de oralização na infância e na adolescência e conheceram a Libras na fase adulta. $\mathrm{Na}$ ocasião da pesquisa, um deles assumia a identidade surda, dois deles estavam em processo transição, passando a assumir sua identidade como surdo, enquanto um deles tinha a identidade surda incompleta. Todos reconheceram que a Libras trouxe um novo significado para suas vidas. Conclui-se que os surdos vivenciam situaçôes cotidianas em que a negação e a aceitação da surdez estão relacionadas à forma como são interpelados em um contexto marcado por preconceitos que geram obstáculos quanto à sua inserção na sociedade, dada a dificuldade de comunicação com os ouvintes. Nesse sentido, todos os sujeitos da pesquisa afirmaram que se a sociedade ouvinte conhecesse e usasse a Libras como língua oficial do País, as experiências vivenciadas teriam uma conotação positiva.

PALAVRAS-CHAVE: Surdez; Libras; Identidades surdas.

ABSTRACT: This article deals with a reflection on the identities of the deaf subject, verifying aspects related to the denial or acceptance of deafness and the Brazilian Sign Language (Libras). The researched audience consisted of four deaf adults participating in an extension project at the Federal University of Viçosa, Minas Gerais. The methodological approach was qualitative, based on a case study, whose data collection was based on semi-structured interviews. The investigative process revealed that the research participants went through oralization processes in childhood and adolescence and knew Libras in adulthood. At the time of the research, one of them assumed

\begin{tabular}{|l|l|l|l} 
Revista Linguagem em Foco & Fortaleza, CE & v. 11 n. 2 & ISSN 2674-8266
\end{tabular}

\section{Linguagęm Foco \\ Revista do Programa de Pós-Graduação em Linguística Aplicada da UECE}

Fúlvia Ventura Leandro, mestrado em Economia Doméstica pela Universidade Federal de Viçosa (UFV).

Michelle Nave Valadáo, professora adjunta do Departamento de Letras da Universidade Federal de Viçosa (UFV).

Rita de Cássia Pereira Farias, professora adjunta do Departamento de Economia Doméstica da Universidade Federal de Viçosa (UFV). Viçosa-MG.

Distribuído sob

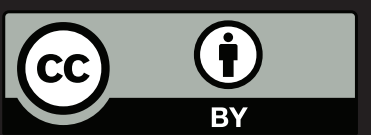


deaf identity, two of them were in the process of transition, assuming their identity as deaf, while one of them had incomplete deaf identity. Everyone recognized that Libras brought new meaning to their lives. It is concluded that deaf people experience everyday situations in which denial and acceptance of deafness are related to the way they are challenged in a context marked by prejudices that generated obstacles to their insertion in society, given the difficulty of communication with listeners. In this sense, all the research subjects stated that if the listener society knew and used Libras as the official language of the country, the lived experiences would have a positive connotation.

KEYWORDS: Deaf; Libras; Deaf Identity.

\section{INTRODUÇÃO}

O número de indivíduos surdos ou que possuem algum grau de surdez no Brasil é relativamente alto. Segundo o Instituto Brasileiro de Geografia e Estatística (IBGE), em 2010 havia 9,7 milhōes de brasileiros que possuíam surdez ou alguma deficiência auditiva, o que representa 5,1\% da população.

$\mathrm{Na}$ cidade de Viçosa-MG, pesquisas desenvolvidas pelo Departamento de Letras da Universidade Federal de Viçosa (UFV) apontam que existem aproximadamente 30 indivíduos surdos no município. Alguns desses indivíduos participam de atividades desenvolvidas na universidade, como no projeto de extensão denominado Ensino e Aprendizagem e Metodologias de Ensino para Surdos (EAMES), cuja finalidade é resgatar o processo educacional de jovens e adultos surdos que concluíram o ensino médio e desejam prestar o Exame Nacional do Ensino Médio (ENEM) para ingressar ao ensino superior. O projeto teve início em 2011, com o objetivo de realizar oficinas bilíngues que priorizassem o ensino e a aprendizagem da Língua Portuguesa como segunda língua para os surdos. As oficinas eram desenvolvidas em Libras e ministradas por licenciandos da UFV, orientados pelos professores de Libras do Departamento de Letras da instituição. Posteriormente, o projeto ampliou o seu escopo, oferecendo, além do português e da Libras, oficinas sobre as ciências da natureza e suas tecnologias, bem como de matemática.

A maioria dos surdos participantes do projeto EAMES não tiveram contato com a comunidade surda na infância, relacionando-se predominantemente com ouvintes que se comunicam por meio da Língua Portuguesa, e conhecendo a Libras apenas na fase adulta. A apreensão tardia da Libras implica em múltiplas identidades relacionadas à surdez e envolve relações complexas entre os indivíduos surdos, suas famílias e a sociedade. A compreensão dos fatores que podem contribuir na construçáo das diferentes identidades dos surdos integrantes do referido projeto, bem como a concepçáo de surdez assumida por eles e por aqueles com os quais convivem foram o foco de interesse deste estudo. Em termos conceituais, tal concepção transcorre por duas perspectivas distintas. A perspectiva clínica ouvintista ${ }^{1}$ associa a surdez a uma deficiência ou incapacidade e prevê a recuperação da audição e da fala por meio de intervenções terapêuticas e uso de dispositivos de amplificação sonora. Nessa perspectiva, a normalização cumpre um papel essencial de integração do surdo na comunidade ouvinte, visando à aproximação aos padróes estabelecidos como normais pela sociedade (STROBEL, 2007). A segunda perspectiva refere-se ao

1 O termo ouvintista é definido por Skliar (2013, p. 15) como "um conjunto de representaçóes dos ouvintes, a partir do qual o surdo está obrigado a olhar e a narrar-se como se fosse ouvinte".

\begin{tabular}{c|c|c|c}
\hline Revista Linguagem em Foco & Fortaleza, CE & v. 11 n. 2 & ISSN 2674-8266 \\
\hline
\end{tabular}


paradigma social, cultural e antropológico da surdez. Nesse âmbito, a surdez é compreendida como uma diferença linguística e cultural, marcada por experiências visuais (PERLIN, 2013). Por esse viés socioantropológico é possível aceitar o conceito de cultura surda em uma leitura multicultural, tendo em vista que os surdos se relacionam em uma sociedade constituída predominantemente por pessoas ouvintes, mas também convivem em uma comunidade composta por surdos, onde compartilham de uma historicidade em comum e de artefatos culturais que emergem das experiências vivenciadas na ausência da audição (SKLIAR, 2013).

A concepção assumida implica no desenvolvimento de diferentes açóes que influenciam as representaçôes que a família, a sociedade e o próprio surdo constroem sobre a surdez, bem como a sua configuração identitária. A partir dessas representaçôes, Perlin (2013) identificou múltiplas identidades surdas, categorizando cinco delas: identidade surda, identidade surda híbrida, identidade surda de transição, identidade surda incompleta e identidade surda flutuante. Essa classificação foi aplicada na análise dos sujeitos da pesquisa, buscando verificar quais configuraçôes identitárias estavam mais presentes entre os surdos participantes, a partir de seus relatos, buscando compreender a aceitação ou negação desses sujeitos sobre a surdez e a Libras.

\section{CONSIDERAÇÓES SOBRE IDENTIDADES: UM REFLEXO DA DIVERSIDADE HUMANA}

O conceito de identidade é amplo. Neste trabalho, buscou-se investigar a identidade relacional, construída no âmbito da cultura e das relações sociais, sendo esta repleta de símbolos, ligada às condiçôes sociais e materiais da vida. Como as identidades são resultantes dos múltiplos processo de interação entre o indivíduo e seus relacionamentos, não existe uma identidade fixa e estável, mas múltiplas identidades que se manifestam de acordo com o momento e o contexto em que o sujeito está inserido.

Sob essa perspectiva, Berlatto (2009) defende que dependendo do contexto social em que o sujeito está inserido, uma configuração identidade pode ser afirmada ou reprimida. Sua construção ocorre no interior de contextos sociais que determinam a posição dos sujeitos, orientando suas representaçôes e suas escolhas. Nesse sentido, quando o indivíduo está inserido em um contexto estigmatizante, ele pode ocultar sua identidade. Por outro lado, quando o grupo social compartilha dos mesmos interesses, pode demonstrar a sua identidade sem constrangimentos.

Bauman (2005) pondera que as identidades podem estar ligadas a duas concepçóes de grupos: a primeira é quando os membros vivem juntos em um mesmo espaço físico e possuem um elo e uma entidade que os representam. A família representa bem esse primeiro grupo, sendo a primeira instituição em que um indivíduo mantém um relacionamento social. A segunda forma é composta por pessoas ligadas por afinidades, ideias, princípios e valores comuns, o que os levam a ter identidades convergentes. Em se tratando de surdos, esse segundo grupo pode estar relacionado à comunidade surda, que compartilha de uma mesma língua e um processo histórico-cultural congruente.

$\mathrm{O}$ autor ainda considera que as identidades estão à disposiçấo dos sujeitos, podendo ser resultados da escolha de cada um, ou sofrer influências impostas por grupos sociais aos quais os indivíduos pertencem. Desse modo, o indivíduo pode apresentar uma identidade que não condiz com a sua maneira de pensar 
e estar no mundo, mas ser o resultado da imposição de algum desses grupos.

Assim, os grupos internos, como da família, ou os grupos externos, que compartilham ou não de princípios em comum, influenciam na construção das identidades dos sujeitos. Nesse contexto, a identidade não é estática, mas é móvel e flexível, possibilitando que um mesmo indivíduo possua diferentes identificações de acordo com o meio social em que está momentaneamente inserido (HALL, 2004).

A identidade também possui um caráter dinâmico e multifacetado, daí a existência da pluralidade de identidades. Hall (2004) ressalta que se a identidade está sujeita ao contexto em que o indivíduo está inserido, as transformaçôes ocorridas no mundo moderno, em todas as esferas sociais, culturais e econômicas, desestabilizariam as identidades, levando-o a um processo continuo de mutação. Para mostrar como a concepção de identidade é cambiante, o autor traçou três concepçóes de identidades: a identidade do sujeito do Iluminismo, do sujeito sociológico, e do sujeito pós-moderno.

A identidade do sujeito do Iluminismo se baseia em uma concepção da pessoa humana como indivíduo integralmente centrado, possuidor de uma essência interior que aparece quando o sujeito nasce e com ele se desenvolve. Essa essência interior permanece inalterada ao longo da existência do sujeito. O sujeito sociológico compreende que a essência interior do sujeito não é independente e autossuficiente, mas construída na relação e interação entre o sujeito e a sociedade em que está inserido. Já a perspectiva do sujeito pós-moderno considera que o sujeito é definido historicamente, e não biologicamente, assumindo múltiplas identidades em diferentes momentos.

Nesta pesquisa, a identidade do sujeito pós-moderno é a que mais se aproxima da experiência dos sujeitos surdos. Ela compreende um indivíduo que não está preso a uma identidade estável e única, mas que se modifica a partir de sua inter-relação com o meio, mostrando que a identidade não é inata, mas construída historicamente. Assim, concordamos com Hall (2004) ao definir que "a identidade torna-se uma 'celebração móvel' transformada continuamente em relação às formas pelas quais somos representados ou interpelados pelos sistemas culturais que nos rodeiam” (p. 13). Adicionalmente, Bauman (2005) argumenta que "o pertencimento e a identidades não tem a solidez de uma rocha, não são garantidos para toda a vida, são bastante negociáveis e revogáveis” (p. 17).

Nessa perspectiva, na análise das configuraçôes identitárias dos surdos, partimos do entendimento de que a identidade é resultado de uma construção social que envolve múltiplos processos e relações complexas. Conforme Moser e Damke (2012), a identidade do sujeito se constrói a partir de sua interação na sociedade, cujo processo é mediado pelas práticas linguísticas, sociais e culturais. Tais construçôes são passíveis de transformação decorrentes das mudanças socioculturais, das relaçóes de poder estabelecidas e da percepção dos sujeitos frente ao contexto sociocultural no qual estão inseridos.

\section{AS IDENTIDADES SURDAS}

Para compreender aspectos inerentes às identidades surdas é importante considerar a surdez a partir dos paradigmas social, cultural e antropológico, como uma diferença linguística e cultural, cujo artefato mais marcante é o uso da língua de sinais (PERLIN, 2013). Para Perlin (2013), a identidade dos surdos 
como sujeitos culturais foi por muito tempo reprimida devido aos processos de oralização exclusiva, pautados nas concepçôes clínico- terapêuticas da surdez. Para autora:

[...] é evidente que as identidades surdas assumem formas multifacetadas em vista das fragmentaçôes a que estấo sujeitas face a presença do poder ouvintista que lhes impóe regras, inclusive, encontrando no estereótipo surdo uma resposta para a negação da representação da identidade surda ao sujeito surdo (PERLIN, 2013, 62).

Ela reconhece que as identidades surdas estão em construção e são "frequentemente transformadas", empurrando "o sujeito em diferentes posiçôes" (p. 42). A partir dessa concepção, a pesquisadora identificou cinco identidades: Identidade Surda, Identidade Surda Híbrida, Identidade Surda de Transição, Identidade Surda Incompleta e Identidade Surda Flutuante, conforme deescrição a seguir.

Essas identidades são alvo de permanentes discussóes entre os próprios surdos, pois há aqueles que utilizam a língua de sinais e convivem em comunidades surdas, e os que se representam a partir da cultura ouvinte, sendo estes oralizados, ou seja, fazem uso de uma língua de modalidade oral, como a Língua Potuguesa.

Sobre os surdos oralizados, Lane (1992), apud Oliveira e Santos (2010), ressalta que o processo de oralização não considera o indivíduo surdo, mas os interesses dos ouvintes, suprimindo seu maior patrimônio cultural, que é a língua de sinais. Esse aspecto é corroborado pela maioria dos autores que defendem que a Identidade Surda é constituída a partir de experiências com o uso da língua de sinais, como Perlin (2013), Silva (2010) e Skliar (2013).

Considerando que as identidades se constroem no interior das relaçóes, Perlin (2013) ressalta que o indivíduo que tem a Identidade Surda em evidência recria um espaço cultural diversificado e busca sempre estar em contato com outros surdos. Assim, sua identidade vai se formando a partir de experiências visuais centradas no ser surdo, até se constituir em uma identidade política surda. Sá (2001) também afirma que as experiências visuais que acontecem no encontro surdo-surdo, em comunidades surdas, determinam modos de comportamentos semelhantes entre eles, resultando em uma identidade que se caracteriza pela luta política e por direitos de serem respeitados enquanto cidadãos com especificidades linguísticas e culturais.

Portanto, para os pesquisadores supracitados, a identidade cultural surda evidencia as semelhanças entre os surdos e o distanciamento do jeito ouvinte de ser, sendo fundamentada na língua de sinais e na valorização das experiências visuais decorrentes da condição física imbricada pela surdez. Segundo Skliar (2013), os surdos que desenvolvem a Identidade Surda se reconhecem pela condição de vivenciarem o mundo sem escutar, já que não dispóem do sentido da audição, e fortalecem e compartilham costumes e práticas próprias que são alicerçadas na forma como compreendem e se relacionam por meio da experiência visual. Dessa maneira, a Identidade Surda se constrói, se assume e se desenvolve em contato com outros surdos com identidade semelhante, que estão imersos em uma mesma cultura.

Em relação à Identidade Híbrida, esta é formada pela união de culturas diferentes e não possui apenas uma raiz ou origem. Hall (2004) aponta essa identidade como "uma celebração móvel, formada e transformada continuamente em relação às formas pelas quais somos representados ou interpelados nos 
sistemas culturais que nos rodeiam" (p. 13).

A Identidade Surda Híbrida refere-se às transformaçôes que acontecem quando um surdo nasce ouvinte e com o passar do tempo torna-se surdo. Essa identidade carrega um pouco dos dois mundos: o mundo surdo e o mundo ouvinte, uma vez que o sujeito possuidor dessa identidade participma de ambas os experiências. O surdo que possui a Identidade Híbrida pode se expressar por meio da língua oral e da língua de sinais, usando-as de acordo com o sistema cultural a que for interpelado. Porém, de acordo com Perlin (2013), o surdo possuidor dessa identidade, embora híbrida, pode reivindicar a identidade surda como algo político ao participar das comunidades surdas e assumir um comportamento surdo de ser.

A Identidade Surda de Transição, por sua vez, se caracteriza como imprecisa, o que remete à ideia de uma identidade fragmentada, como apontado por Hall (2004). Na concepção de Bauman (2005), o surdo com essa identidade é aquele que tendo vivido em uma situação de identidade cativeiro, ficou por muito tempo sem poder manifestar suas preferências, tampouco falar por si. A transição acontece no momento em que o surdo entra em contato com a comunidade surda e, a partir dessa convivência, começa a incorporar os aspectos da identidade surda, distanciando-se cada vez mais dos modelos de representação ouvinte. Para muitos surdos brasileiros, esse contato acontece somente na adolescência.

Perlin (2013) destaca que as marcas da representação ouvinte sempre estarão presentes na Identidade de Transição, pois as experiências que tiveram no mundo ouvinte influenciam a constituição dessa identidade, que agora se complementa com os aspectos da Identidade Surda, sem apagar os aspectos que trouxe da identidade ouvinte.

Já a Identidade Surda Incompleta se compõe fundamentalmente de representaçôes ouvintes, ocasionadas pela restrição das relaçôes sociais dos surdos com ouvintes, apenas. Nesse sentido, o surdo é arrebatado para a representação ouvinte de ser e não consegue se desvencilhar disso. Perlin (2013) ressalta que essa é uma identidade que está condicionada às expectativas que os ouvintes depositam sobre os surdos. Dessa forma, os surdos buscam reproduzir a identidade ouvinte, sendo esta vista como superior à Identidade Surda. Essa formação acontece em espaços sociais de convívio com ouvintes e longe de outros surdos. Neste caso, existe uma subordinação, pois trata-se de uma identidade imposta. A esse respeito, Perlin (2013) tece o seguinte comentário:

Há casos de surdos cujas identidades foram escondidas, nunca puderam encontrar-se com outros surdos, conseguiram adentrar-se no saber junto aos ouvintes e há casos de surdos mantidos em cativeiros pela família onde se tornaram incapacitados de chegar ao saber de se decidirem por si mesmos (PERLIN, 2013, p. 65).

Finalmente, a Identidade Surda Flutuante se constitui também a partir da representação ouvinte, mas ao contrário da identidade surda incompleta, em que o surdo é subordinado a uma ideologia ouvinte, sendo proibido de se encontrar com outros surdos. Na Identidade Flutuante o surdo geralmente é consciente da sua surdez, porém se manifesta a partir da representação ouvinte por sua própria vontade, desprezando assim a cultura surda. Essa identidade não contém muitos aspectos da Identidade Surda, haja vista que sua intenção é se parecer o mais próximo possível com os ouvintes. Perlin (2013) destaca que, embora o surdo assuma uma identidade ouvinte, sua identidade é fragilizada, pois por mais que a tecnologia dos aparelhos auditivos esteja avançada e o surdo faça uso dela, ele nunca deixará de ser surdo, 
assim como nunca chegará a ser um ouvinte de fato.

Importa mencionar que essa classificação não visa enquadrar os surdos em identidades formatadas, prontas e estáticas; ao contrário, mostra como as identidades surdas são complexas e dinâmicas, e estão sempre em construção. A partir das identidades descritas por Perlin (2013), é possível perceber que os surdos podem assumir diferentes identidades de acordo com a sua aproximaçáo ou o seu distanciamento da comunidade surda, e com as relações que são estabelecidas entre surdos e surdos, e surdos e ouvintes.

Diante do que foi exposto, acreditamos que as identidades surdas descritas corroboram com a identidade pós-moderna proposta por Hall (2004), apresentando-se como identidades fragmentadas que contêm múltiplos aspectos de todas as identidades disponíveis na sociedade. Baseada em Hall (2004), Perlin (2013) observa que "[...] a identidade parte da comunidade surda, sem esquecer as identidades ouvintes que lhe emprestam fragmentos, constituem-se novas visóes" (p. 66). Portanto, a identidade surda não se constitui sozinha, não é limitada nem completa em si mesmo, ao contrário, é formada e forjada por aspectos das identidades surdas e ouvintes, ainda que de maneira imposta ou nâo perceptível.

\section{PERCURSO METODOLÓGICO}

A pesquisa foi realizada com sujeitos surdos participantes do projeto EAMES, desenvolvido na Universidade Federal de Viçosa (UFV), uma vez que esse projeto, no momento da pesquisa, se constituía no ambiente com maior número de surdos da cidade. $\mathrm{Na}$ ocasiáo da coleta de dados, apenas quatro surdos frequentavam assiduamente o projeto e, portanto, constituíram o universo pesquisado.

A abordagem metodológica foi qualitativa, baseada em um estudo de caso. A coleta de dados ocorreu a partir de entrevistas semiestruturadas realizadas individualmente com os surdos, em Libras, e filmadas. As entrevistas iniciaram-se no mês de setembro de 2016 e seguiram até o mês de novembro do mesmo ano, totalizando um período de três meses, e abarcaram questóes sobre a percepção dos surdos diante da surdez, do processo de reabilitação, das relaçóes entre surdos e ouvintes, e da língua de sinais.

Visando atender aos aspectos éticos, o projeto de pesquisa foi submetido ao Comitê de Ética em Pesquisa com Seres Humanos (CEP) da Universidade Federal de Viçosa para avaliação, recebendo aprovação sob o $\mathrm{n}^{\mathrm{o}}$ CAAE 57970816.3.0000.5153. Todos os participantes assinaram o Termo de Consentimento Livre e Esclarecido (TCLE), e, havendo concordância espontânea e consentimentos, todos os processos metodológicos foram desenvolvidos.

A análise dos dados se deu a partir do método hermenêutico dialético, por atender uma possibilidade de interpretação mais aproximada da realidade. Para Minayo (1992), a hermenêutica dialética busca:

[...] entender o texto, a fala, o depoimento, como resultante de um processo social (trabalho e dominaçáo) e processo de conhecimento (expresso em linguagem) ambos frutos de múltiplas determinaçôes mas com significado específico. Esse texto é a representação social de uma realidade que se mostra e se esconde na comunicação, onde o autor e o intérprete são parte de um mesmo contexto ético-político" (MINAYO, 1992, p. 227).

Os dados coletados foram organizados e sistematizados para análise. Inicialmente foi feita a tradução para a Língua Portuguesa e a posterior transcrição de todas entrevistas. Em seguida, realizou-se a leitura 
preliminar do material, o que possibilitou a classificação dos temas. Depois de transcritas, as informaçóes foram classificadas de acordo com os seguintes tópicos: surdez; Libras; uso de dispositivos de amplificação sonora; relações sociais entre surdos e ouvintes. Com isso, foi possível estabelecer uma articulação entre os dados coletados e os referenciais teóricos da pesquisa, para dar base ao objetivo formulado de refletir sobre as identidades dos surdos aprticipantes do projeto.

\section{RESULTADOS E DISCUSSÓES}

Os participantes da pesquisa encontravam-se na faixa etária entre 23 e 30 anos, sendo dois do gênero feminino e dois do gênero masculino. Três surdos eram da mesma família, dois irmãos e um primo. Todos os surdos do estudo eram filhos de pais ouvintes. A renda familiar variava entre dois e três salários mínimos.

Quanto à escolarização, três possuíam ensino médio completo e uma estava cursando o ensino superior. Eles participavam do projeto EAMES desde 2011, a fim de adquirirem conhecimentos para pretar o ENEM. Uma das participantes, mesmo após ingressar na faculdade, continuou a frequentar o projeto para complementar sua formação.

Em relação aos níveis auditivos, todos apresentavam surdez congênita, sendo que em três deles a surdez era bilateral de grau profundo, e em uma entrevistada a surdez era de grau moderado a profundo, conforme demonstrado na tabela 1 .

Tabela 1 - Caracterizaçáo dos surdos

\begin{tabular}{|c|c|c|c|c|c|c|c|}
\hline Nome $^{2}$ & Gênero & Idade & $\begin{array}{l}\text { Estado } \\
\text { civil }\end{array}$ & Escolaridade & $\begin{array}{c}\text { Grau da } \\
\text { surdez }\end{array}$ & $\begin{array}{c}\text { Constituiçáo } \\
\text { Familiar }\end{array}$ & Renda Familiar \\
\hline Ruan & Masculino & 29 & Solteiro & $\begin{array}{l}\text { Ensino médio } \\
\text { completo }\end{array}$ & $\begin{array}{l}\text { Congênita } \\
\text { profunda }\end{array}$ & $\begin{array}{c}\text { Mora em Guaraciaba } \\
\text { com a mãe, o pai e a } \\
\text { irmã RE }\end{array}$ & $\begin{array}{c}\text { Até três salários } \\
\text { mínimos }\end{array}$ \\
\hline Regina & Feminino & 30 & Solteira & $\begin{array}{l}\text { Ensino superior } \\
\text { incompleto }\end{array}$ & $\begin{array}{l}\text { Congênita } \\
\text { profunda }\end{array}$ & $\begin{array}{c}\text { Mora em Guaraciaba } \\
\text { com a mãe, o pai e o } \\
\text { irmão RR }\end{array}$ & $\begin{array}{l}\text { Até três salários } \\
\text { mínimos }\end{array}$ \\
\hline Téo & Masculino & 23 & Solteiro & $\begin{array}{l}\text { Ensino médio } \\
\text { completo }\end{array}$ & $\begin{array}{l}\text { Congênita } \\
\text { profunda }\end{array}$ & $\begin{array}{l}\text { Mora em Guaraciaba } \\
\text { com a mãe, o pai e a } \\
\text { irmã mais nova ouvinte }\end{array}$ & $\begin{array}{c}\text { Até dois salários } \\
\text { mínimos }\end{array}$ \\
\hline Ada & Feminino & 29 & Solteira & $\begin{array}{l}\text { Ensino médio } \\
\text { completo }\end{array}$ & $\begin{array}{l}\text { Congênita } \\
\text { moderada à } \\
\text { profunda }\end{array}$ & $\begin{array}{c}\text { Mora em Viçosa com } \\
\text { a máe }\end{array}$ & $\begin{array}{c}\text { Até dois salários } \\
\text { mínimos }\end{array}$ \\
\hline
\end{tabular}

Fonte: Dados da Pesquisa (2017).

Em seus relatos, os participantes afirmaram que as causas da surdez são desconhecidas, porém três deles suspeitam que a surdez foi hereditária, uma vez que seus pais são primos. O diagnóstico da surdez, de acordo com os entrevistados, foi descoberto após os três anos de idade, sendo iniciados em processos de reabilitaçáo com o uso de aparelhos auditivos e terapia para desenvolvimento da fala oral.

A falta de comunicação dos surdos com os ouvintes, inclusive no núcleo familiar, foi uma situação

2 Com o intuito de preservar a identidade dos surdos, para identifica-los, foram utilizados nomes fictícios

\begin{tabular}{l|l|l|r} 
Revista Linguagem em Foco & Fortaleza, CE & v. 11 n. 2 & ISSN 2674-8266
\end{tabular}


presente em suas vidas, como pode ser observado nos seguintes relatos:

No passado eu tinha muita dificuldade, então eu ficava apontando o dedo. Por exemplo, se eu queria água eu apontava o dedo...não sabia Libras então era muito difícil, tudo era por apontação e gestos. Quando fui estudar na APAE também não conseguia me comunicar. Só através da apontação (Téo, 23 anos).

Minha família não sabe Libras, para se comunicar comigo, utilizam de gestos e apontação, meus primos, minha família eles conversam em língua oral...eu não entendo nada. Meu pai não sabe Libras, acha difícil aprender. Minha mãe e minha irmã sabem um pouquinho só, e minha vó sabe alguns sinais relacionados aos animais da roça: boi, cavalo... mas a maioria se comunica comigo por gestos mesmo, ou escrevem no papel (Téo, 23 anos).

Perlin (2013) postula que é frequente a desinformação das famílias sobre as especificidades dos surdos e sobre a língua de sinais, pelo fato de elas priorizarem as orientaçóes dos médicos e dos fonoaudiólogos que, frequentemente, valorizam a oralização. De fato, todos os surdos entrevistados realizaram tratamentos com fonoaudiólogos para o desenvolvimento da fala oral durante boa parte da vida, como pode ser observado nos relatos a seguir: Eu sempre fiz tratamento fonoaudiólogo para aprender a falar. Na APAE não tinha Libras, então nós
fazíamos tratamento com fonoaudiólogo. Hoje eu não faço mais não (Regina, 30 anos).

No passado quando eu ia na fonoaudióloga eu falava um pouco, poucas palavras mas falava oralmente, mas era difícil falar [...] depois que aprendi a Libras desisti da fala oral (Téo, 23 anos).

Sempre fui ao fonoaudiólogo desde criança, falar é muito bom, eu gosto. Gosto da Libras mais ou menos, porque tenho que aprender [... ]é difícil. Mas eu gosto de falar e de Libras igual (Ada, 29 anos).

Em relação a Libras, os quatro surdos entrevistados afirmaram ser usuários da língua. Contudo, uma participante, além de utilizar a Libras, é também oralizada, ou seja, se comunica utilizando a Língua Portuguesa na modalidade oral.

Os surdos em questão conheceram a língua de sinais relativamente tarde, após os 18 anos de idade. Dizeu e Caporalli (2005) defendem que a criança surda seja colocada próximo de seus pares e em contato com um adulto surdo fluente em Libras, preferencialmente antes dos três primeiros anos de idade, para que a aprendizagem ocorra de maneira mais fácil e natural, fazendo parte do repertório cultural da criança surda.

Perlin (2013) relata que o conhecimento tardio da língua de sinais pelos surdos é comum, pois a maioria deles provém de famílias ouvintes que desconhecem a importância dessalíngua e suas especificidades. Além disso, no Brasil, a oficialização da Libras aconteceu somente em 2002 e, anteriormente a essa data, o conhecimento da língua de sinais era restrito e sem legitimidade, desenvolvido principalmente em locais informais. Atualmente os surdos são amparados pelo Decreto 5.626 de 2005 (BRASIL, 2005), e contam com o direito a uma educação bilíngue, que tem Libras como a primeira língua do surdo e a Língua Portuguesa como sua segunda língua, na modalidade escrita ou oral.

Nenhum dos surdos afirmou dispensar o uso da Libras, mas alegaram procurar viver, ou se adaptar, aos dois mundos: dos surdos, através da Libras, e dos ouvintes, por meio da Língua Portuguesa. Com base 
em Perlin (2013), esses surdos podem ser identificados como possuintes da identidade de transição, cujo contato com a Libras e com a comunidade surda foi tardio.

Nesse sentido, Hall (2004) ressalta que essa identidade se refere a uma identidade múltipla e fragmentada, que sofre fortes influências e se altera em função dos espaços e tempos de referência, por estarem em constante transformação. Para o autor, essas identidades estáo em crise, e por isso os sujeitos lutam pela própria estabilidade e pela organização de uma nova identidade, como também pela identificação com o grupo e com o lugar em que habitam. Nesse novo cenário, formam-se novas identificações, que se tornam múltiplas, menos estáticas e centralizadas.

Ainda de acordo com Hall (2004), não existe mais uma identidade mestra, um único centro de identidade que legitima e determina a ordem social. Nesse novo processo, as identidades são múltiplas e fragmentadas, como é o caso de Ada, que parece possuir a identidade incompleta e de transição. Para ela, a cultura ouvinte é vista como melhor que a cultura surda, e a Libras não tem grande significado no seu cotidiano. Sobre esse aspecto, notamos que Ada, embora seja oralizada, teve sua oralização demorada, o que trouxe muitas falhas na comunicação. Por isso ela não compreende o significado de muitas palavras da Língua Portuguesa e também não domina plenamente a Libras. Essa situação foi percebida diversas vezes durante a entrevista, nos momentos em que ela recorreu à escrita para a comunicação, e, ainda assim, de maneira rudimentar. Com base na perspectiva de Hall (2004) e de Perlin (2013), comrpeendemos que Ada está construindo e desconstruindo suas identidades, o que faz parte de um conceito de identidade pós-moderna, fragmentada e inconstante.

Dentre os participantes desta pesquisa, Ada iniciou o aprendizado em Libras somente depois dos 25 anos de idade, com uma professora ouvinte de um projeto da UFV. A esse respeito, Quadros (2006) defende que a aprendizagem de Libras pelo surdo, ainda que tardiamente, deve ser transmitida de surdo para surdo, para que, além da Libras, ele desenvolva também aspectos da identidade e da cultura surda. Dos quatros surdos entrevistados, apenas Téo afirmou que a Libras é suficiente para ele:

O aparelho de amplificação sonora eu sempre usei, mas agora eu tirei. Ele fazia muito barulho, me incomodava. Eu não queria mais, e como eu estava muito bem na Libras eu tirei e não uso mais aparelho. Gosto da Libras, o aparelho não me faz falta (Téo, 23 anos).

Nesse sentido, de acordo com Perlin (2013), Téo seria o único do grupo entrevistado a possuir a identidade surda propriamente dita, que seria a identidade centrada no "ser surdo", fazendo uso apenas da comunicação em Libras e da experiência visual.

Dois surdos entrevistados, Ruan e Regina, ainda apresentam a identidade de transição, pois embora tenham vivido boa parte de suas vidas no mundo dos ouvintes, ao se depararem com a língua de sinais e com a comunidade surda, se identificaram e passaram a usá-la como principal meio de comunicaçáo. Entre eles, Regina é a que mais se aproxima da identidade surda.

De modo geral, pode-se dizer que todos os surdos entrevistados apresentam marcas da cultura ouvinte e vivenciam, em algum momento, um conflito cultural entre a identidade surda e a identidade ouvinte.

Quanto ao relacionamento social, três entrevistados relataram que não possuem muitos amigos, pois não costumam frequentar lugares onde se concentra um grande número de jovens de suas idades.

\begin{tabular}{c|c|c|c}
\hline Revista Linguagem em Foco & Fortaleza, CE & v. $11 \mathrm{n} .2$ & ISSN 2674-8266 \\
\hline
\end{tabular}


Mencionam que se sentem sozinhos e deslocados pela falta de comunicação, como pode ser notado nos depoimentos:

\begin{abstract}
Eu gosto de ir à igreja, não gosto de ir a festas, forró...eu me sinto sozinho. Em Guaraciaba, todo lugar que eu vou sempre me sinto sozinho, as pessoas são ouvintes só eu sou surdo. Meu irmáo é ouvinte, eu peço ele para interpretar para mim, mas ele não sabe Libras. Então eu prefiro ficar em casa dormindo. Quando encontro o Téo a gente conversa em Libras é muito bom. Na igreja também não tem intérprete, mas eles rezam eu participo da óstia... Minha irmá gosta de sair, eu gosto de ficar em casa (Ruam, 29 anos).

Não tenho muitos amigos, mas a maioria dos meus amigos são surdos aqui em Viçosa e em Ponte Nova, os amigos ouvintes que tenho são intérpretes (Ruan, 29 anos).

Meus amigos são Regina e Ruan, amigos ouvintes eu tenho poucos (Ada, 29 anos)
\end{abstract}

Já a participante Regina alegou frequentar qualquer local, sem nenhum problema, uma vez que possui muitos amigos, tanto surdos quanto ouvintes:

Tenho muitos amigos, surdos e ouvintes, a maioria são ouvintes, mas em Ponte Nova tenho muito amigos surdos. Eu ensino Libras para meus amigos ouvintes ou eles fazem datilologia (Regina, 30 anos)

Todos os surdos admitiram que assim como acontece nas relaçôes familiares, a principal dificuldade em seus relacionamentos sociais está atrelada à comunicação. Dizeu e Caporali (2O05) ressaltam que a sociedade ainda não está preparada para receber o indivíduo surdo, portanto não lhe proporciona as condiçóes de desenvolvimento e consolidaçáo da linguagem por meio de interaçóes comunicativas, já que poucas pessoas conhecem ou sabem se comunicar em Libras.

Contudo, dois surdos afirmaram que após conhecerem a língua de sinais, além de suas relaçóes sociais terem ampliado, elas se tornaram mais efetivas. Nesse âmbito, Figueiredo (2010) observa que a língua de sinais para o surdo não é só um fator linguístico, mas também de fortalecimento de identidade e da cultura surda. Quando os surdos afirmam que após a apreensão da língua de sinais os laços sociais se expandiram, significa que a língua de sinais trouxe, entre tantas coisas, autonomia para participarem com mais efetividade da sociedade. Dizeu e Caporali (2005) ainda destacam que quando o surdo adquire uma língua estruturada, ele obtém conhecimentos e oportunidades que o estimulam a participar ativamente do convívio na sociedade. Esse convívio também passa a acontecer em situaçóes em que, aparentemente, não ocorre a participação de surdos, como declaram Regina e Téo:

Gosto muito de dançar também, principalmente forró, eu não ouço nada da música, mas sinto! (Regina, 30 anos).

Uma vez fui a uma festa, dancei com uma menina ouvinte e a gente namorou foi legal! (Téo, 23 anos).

Figueiredo (2010) aponta que o surdo só conquistará sua autonomia quanto desenvolver a identidade surda, e isso só acontece por meio do contato com a comunidade surda, pois "é através do encontro com os saberes surdos, nas histórias de vida, nas relaçóes com o mundo e com o outro é que vai 
haver a possibilidade de se interagir socialmente" (FIGUEIREDO, 2010 p. 26).

Em Viçosa, cidade onde os surdos foram entrevistados, a comunidade surda se organiza, principalmente, a partir dos projetos alocados na UFV ou de encontros em associaçóes em outro município. Quanto ao projeto EAMES, o participante Téo diz que recebeu o convite em 2011 e também convidou Ruan para ir, mas no primeiro momento ele não se interessou, então Téo foi sozinho.

Quando cheguei aqui, vi que a professora conversava em Libras, então eu perguntei: você é surda? Ela me disse: Não, sou ouvinte...

Mas ela falava Libras e nós conversamos, então eu fiquei muito feliz. E chamei o Ruan novamente para participar e ele aceitou, meu desejo é sempre continuar participando do projeto (Téo, 23 anos).

O projeto EAMES, além de seu objetivo inicial, é também um espaço onde a comunidade surda se encontra para estar perto dos seus pares, podendo, assim, interagir e conversar em Libras. A partir desse espaço, os surdos estabeleceram uma rede de relacionamentos, e quando há algum evento ou encontro entre surdos eles divulgam no projeto e todos têm a oportunidade de participar.

Embora não tenha associação de surdos na cidade de Viçosa/ MG, os surdos da pesquisa frequentam a Associação dos Surdos de uma cidade próxima, Ponte Nova, conforme mencionado:

Na associação de Ponte Nova a gente contribui, conversa, e interage, participamos dos eventos e de confraternizaçóes. Eu gosto muito (Ruan, 29 anos).

Apesar da constante luta dos surdos para se autoafirmarem como minoria linguística e cultural, o preconceito, os estigmas da deficiência ainda são constantes. Dos quatro surdos entrevistados, três, Regina, Téo e Ruan, mencionaram situaçóes desagradáveis e preconceituosas por eles vivenciadas, que acreditam ser decorrentes da surdez:

Na minha cidade já percebi algumas pessoas passarem por mim e nem me cumprimentarem (...) (Regina, 30 anos).

Uma vez cheguei perto de uma moça porque queria namorá-la, mas quando ela percebeu que eu era surdo ela foi embora (Téo, 23 anos).

Uma vez, na festa junina, um homem passou por mim, me olhou e fez o sinal de negativo com o polegar para baixo. Eu fiquei com vergonha (Ruan, 29 anos).

O fato dos surdos não ouvirem e utilizarem uma língua de modalidade diferente, na maioria das vezes desconhecida pela sociedade, pode ocasionar essas situações preconceituosas. Isso acontece, segundo Goffman (2004), porque as pessoas ainda esperam que os sujeitos, especilamente àqueles com deficiência, se enquadrem aos padrôes estabelecidos pela sociedade. A ausência de audição dos surdos ocasiona a disseminação da ideia de anormalidade, que influencia e determina normas e estereótipos sobre esses indivíduos, razão pela qual muitos sofrem preconceitos, isolamentos e dificuldades nos relacionamentos sociais.

Embora não tenha muitos amigos e nem frequente muitos lugares, Ada alega nunca ter vivenciado uma situação de preconceito relacionada à surdez. Nessa situação, Goffman (2004) explica que a sociedade muitas vezes mascara o preconceito e tenta suavizar, por meio de elogios ou eufemismos, o preconceito que 
está velado quanto ao indivíduo estigmatizado. Portanto, mesmo que não seja declarado ou percebido, como é o caso de Ada, ainda assim é comum os ouvintes mantenham algumas crenças e preconceitos em relação às pessoas surdas, acreditando que elas não possuem todos os atributos considerados valorativos pela sociedade.

Apesar de vivenciarem situações de preconceito, dois surdos afirmaram não sentir vergonha dar surdez:

\begin{abstract}
No passado eu sofria muito, hoje não, hoje eu sou feliz! Aprendi a ler, precisa estudar e eu gosto. No passado eu tinha vergonha de ser surdo, principalmente na escola. A professora me chamava para ir na frente e eu não ia porque tinha vergonha, hoje não, eu tenho coragem, uso a Libras e falo (Téo, 23 anos).
\end{abstract}

Eu não tenho vergonha de ser surda! (Regina, 30 anos).

A Libras trouxe liberdade e autonomia para Téo que planejava, no futuro, estudar para se tornar veterinário. Já Ruan parece acreditar que o sujeito surdo é inferior ao ouvinte, por não poder realizar as mesmas coisas:

Eu acho que surdo pode ser professor de Libras, eu também já vi surdo policial ... mas surdo médico não! Como o surdo vai examinar o paciente? Como vai ouvir as batidas do coração e do corpo se ele é surdo? (Ruan, 29 anos).

A fala de Ruan evidencia que ele mantém traços de uma imagem do surdo deficiente e limitado, sob o prisma da inferioridade, da subalternidade e da incapacidade. Para ele há uma delimitação do campo de alternativas profissionais para os surdos, já que, em sua concepção, um surdo não poderia ser médico, por exemplo. Nesse processo, Ruan é um exemplo de submissão à cultura ouvinte, reflexos da imposição ouvintista em que o surdo se narra inferior ao sujeito ouvinte.

Para os surdos entrevistados, a melhor forma de inclusão aconteceria se os ouvintes aprendessem a Libras. Pelo fato de poucas pessoas saberem conversar nessa língua, muitos surdos sentem-se excluídos, conforme pode ser percebido na fala de Ruan:

A vida do surdo é difícil porque o ouvinte não sabe Libras. Ser ouvinte é melhor, ser surdo é mais ou menos (Ruan, 29 anos).

Os surdos Téo e Regina também demonstram dificuldades decorrentes de os ouvintes não saberem Libras, conforme expóem:

\footnotetext{
Se o surdo fica perdido em algum lugar, fica complicado, porque quando pede informação as pessoas não sabem Libras então náo conseguem ajudá-lo. Para facilitar eu levo uma foto do lugar que pretendo chegar. A comunicação com a sociedade em geral é difícil, em lojas, com a polícia, em prefeitura (...) seria fácil se as pessoas estudassem Libras (Téo, 23 anos).

Os ouvintes não sabem Libras. Às vezes vou à loja comprar alguma roupa, fica difícil comunicar, é muito importante se todos soubessem Libras (Regina, 30 anos).
}

Com base nos depoimentos, percebe-se que os surdos estão construindo sua identidade surda, 
suas experiências e suas percepçôes de ser surdo, demonstrando fragilidade e, ao mesmo tempo, força. Nesse caso, a força se mostra porque todos eles, até um determinado momento, viveram em um mundo silencioso, em um mundo em que os olhos enxergavam apenas os lábios se movendo, sem significado algum.

Portanto, é inegável perceber o importante papel que a língua de sinais proporcionou aos surdos do estudo, embora alguns deles ainda continuem a perceber a surdez como deficiência e limitação. O fato é que a possibilidade de comunicação trouxe a eles uma nova perspectiva de vida. Se antes eles estavam limitados pelo isolamento linguístico e, consequentemente, social, agora eles vivem sob uma nova perspectiva de vida. Por isso concordamos com Souza (1998), ao afirmar que após os surdos adquirirem a língua de sinais, se reunirem em associaçôes e se constituírem como grupo, eles começaram a ter a possibilidade de refletir sobre um mundo de discursos sobre si próprios. Desse modo, alcançaram um espaço favorável para o desenvolvimento ideológico da própria identidade. Identidade esta que não está pronta, e isso pode ser comprovado nos discursos muitas vezes incoerentes e inconscientes, mas que demonstram ser o início de novas construçóes, subjetividades e identidades. Assim, a Libras surge como uma diretriz nesse novo caminho, que para os surdos deste estudo, em alguns momentos, parecia ser escuro e solitário.

\section{CONSIDERAÇÓES FINAIS}

Neste trabalho avaliou-se a percepção da identidade surda pelos sujeitos surdos, cujo objetivo foi verificar a negação ou a aceitação da surdez e da Libras por parte deles.

A pesquisa possibilitou desvelar importantes aspectos da visão dos surdos sobre as suas diferentes identidades surdas. A partir das análises, constatou-se que uma surda, Ada, apresenta a identidade incompleta, com alguns aspectos da identidade de transição; dois surdos, Ruan e Regina, possuem identidade de transição; e apenas um deles, Téo, já se aproxima da identidade surda propriamente dita. Todos os surdos passaram pelo processo da oralização, porém sem grande êxito. Apenas Ada utiliza mais a língua oral do que a língua de sinais, embora sua oralização seja de difícil entendimento.

Os surdos revelaram que antes de conhecer a língua de sinais levavam uma vida sem muita comunicação e compreensão de mundo. No entanto, após adquirirem a Libras, a vida ganhou novo significado, pois passaram a se comunicar e entender o mundo, além de conquistar mais autonomia. Descreveram ainda situaçóes de preconceitos que vivenciaram e ainda vivenciam cotidianamente, o que demonstra que a sociedade, em geral, não os reconhecem, segundo a concepção socioantropológica, como possuidores de uma língua e cultura própria e de identidades diferenciadas.

Este estudo aponta a relevância da Libras na vida dos surdos entrevistados, destacando o quanto suas histórias foram modificadas a partir dela. Para eles, descortinou-se um mundo desconhecido, pois as palavras, antes sem significados, ganharam novas e positivas conotaçóes nas relaçóes sociais. Nesse sentido, é como se a convivência em sociedade realmente tivesse começado a partir do encontro com a língua de sinais.

No entanto, apesar desse desenvolvimento linguístico, a aquisição tardia da Libras não lhes

\begin{tabular}{c|c|c|c}
\hline Revista Linguagem em Foco & Fortaleza, CE & v. 11 n. 2 & ISSN 2674-8266 \\
\hline
\end{tabular}


possibilitou pleno avanço educacional, pois não se pode ignorar o fato de que apenas um deles ingressou no ensino superior.

No que tange aos tratamentos, todos realizaram acompanhamentos com fonoaudiólogos e fizeram uso de aparelhos auditivos. Entretanto, desconhecem as peculiaridades do implante coclear e demonstraram ter receio em relação a essa cirurgia.

Quanto às atividades cotidianas, dois dos quatro surdos levam uma vida social comum, quando comparados aos ouvintes, pois frequentam festas, saem com amigos surdos e ouvintes e afirmaram não sentir vergonha em relação à surdez, chegando mesmo a ter orgulho de todas as conquistas que alcançaram como surdos. Já os outros dois entrevistados levam uma vida mais retraída em relação aos jovens de suas idades, não gostam de frequentar festas e preferem participar de espaços religiosos ou ficar em casa. Esse retrato pode ser atribuído ao fato de que os dois primeiros surdos estáo mais próximos da identidade surda, não se sentindo limitados pela surdez, enquanto os outros dois ainda não conseguiram se despir do estereótipo da deficiência, ou ainda estão aprendendo a lidar com a surdez, o que pode estar relacionado ao preconceito que vivenciam e sentem até mesmo no ambiente familiar.

Os resultados alcançados mostraram que as identidades dos surdos entrevistados foram construídas socialmente e envolveram relaçóes complexas entre o indivíduo, a família e a sociedade, conforme os preceitos de Hall (2004), Bauman (2005), Berlatto (2009) e Perlin (2013).

Os surdos participantes do estudo têm identidades multifacetadas, elaboradas a partir de fragmentos das múltiplas identidades existentes na atualidade, e que essas identidades não são centradas, mas fragmentadas, corroborando os argumentos de Perlin (2013). Ressaltamos ainda que nessa construção identitária as identidades ouvintes forneceram diversos fragmentos e que, a partir do contato com a comunidade surda, os surdos participantes têm buscado suas identidades como membros de um grupo cultural.

Diante dos desafios encontrados na realização deste trabalho, apontamos algumas lacunas que merecem ser investigadas. Nesse sentido, sugerimos futuros estudos em que as identidades surdas sejam mais bem comparadas e examinadas a partir dos relacionamentos entre os surdos e suas famílias ouvintes, comparando-os com aqueles que ocorrem em famílias surdas. Ainda, são necessárias pesquisas sobre a formação das identidades surdas nos espaços de convívio da comunidade surda, como as associaçóes de surdos, a fim de esclarecer melhor o processo de sua formação como identidade social. Destacase a necessidade de investigar as influências das relaçóes que se estabelecem nos espaços escolares na constituição dessas identidades.

\section{REFERÊNCIAS}

BAUMAN, Z. Identidade. Entrevista a Benedetto Vecchi. Tradução: Carlos Alberto Medeiros. Rio de Janeiro: Jorge Zahar Ed., 2005.

BERLATTO, O. A construção da identidade social. Revista do Curso de Direito da FSG, v. 3, n. 5, p. 141-151, 2009. Disponível em: file://C:/Users/F\%C3\%BAlvia/Desktop/242-760-1-PB.pdf. Acesso em: 18 maio. 2016. 
BRASIL. Decreto $n^{\circ}$ 5.626, de 22 de dezembro de 2005. Regulamenta a Lei ${ }^{\circ} 10.436$, de 24 de abril de 2002, que dispõe sobre a Língua Brasileira de Sinais - Libras, e o art. 18 da Lei no 10.098, de 19 de dezembro de 2000. Brasília: DF, 2005.

DIZEU, L; CAPORALI, S. A língua de sinais constituindo o surdo como sujeito. Educação e Sociedade, v. 26, n. 91, p. 583-597, 2005. Disponível em http://www.scielo.br/pdf/es/v26n91/ a14v2691.pdf. Acesso em: 03 de janeiro de 2017.

FIGUEIREDO, M. M. O. De. Auto Isolamento Ou Exclusão? As Diferentes Visões Sobre Os Surdos. Monografia apresentada à Faculdade Santa Helena, Recife 2010. Disponível em: http://www.suvag. org.br/arquivos/mmof.pdf. 05 de janeiro de 2017.

GOFFMAN, E. Estigma: notas sobre a manipulação da identidade deteriorada. Tradução: Mathias Lambert. $4^{\text {a }}$ ed. Rio de Janeiro: LTC, 2004.

HALL, S. A Identidade Cultural na Pós-Modernidade. 10a ed., Rio de Janeiro: DP\&A, 2004.

IBGE. Censo demográfico 2010 - Características Gerais da População, Religião e Pessoas com Deficiência. Rio de Janeiro: IBGE, 2012.

MINAYO, M. C. de S. O desafio do conhecimento: pesquisa qualitativa em saúde. São Paulo-Rio de Janeiro, HUCITEC-ABRASCO, 1992.

MOSER, F.; DAMKE, C. A construção da identidade na e pela linguagem the construction of theidentity in the and by the language. Revista Travessias, v. 6, n. 15, p. 428-447, 2012.

OLIVEIRA, Z. S. de; SANTOS, T. dos A. da S. Implante Coclear: Limites e Benefícios. Trabalho de Conclusão de Curso. Universidade Estadual de Maringá. 2010.

PERLIN, G. A surdez um olhar sobre as diferenças: Identidades surdas. 6.ed. Porto Alegre: Mediação, 2013.

QUADROS, R. M. Políticas linguísticas e educação de surdos em Santa Catarina: espaço de negociações. Cadernos CEDES. Campinas, v. 26, n. 69, p. 141- 161, 2006.

SÁ, N. L. de. A produção de significados sobre a surdez e sobre os surdos: práticas discursivas em educação. Porto Alegre: UFRGS/FACED/PPGEDU, 2001. (Tese de doutorado).

SILVA, M. do S. Um Olhar Sobre A Identidade Surda. Fórum Nacional de Crítica Cultural 2 Educação básica e cultura: diagnósticos, proposições e novos agenciamentos 18 a 21 de novembro de 2010.

SKLIAR, C. (Org). A surdez um olhar sobre as diferenças. 6a edição. Porto Alegre: Mediação, 2013.

SOUZA, R. M. Que palavra que te falta? Linguística e educação: considerações epistemológicas a partir da surdez. São Paulo: Martins Fontes, 1998.

STROBEL, K. L. História Dos Surdos: Representações "Mascaradas" Das Identidades Surdas. In: Ronice Müller de Quadros e Gladis Perlin (Orgs). Estudos Surdos II. Petrópolis, RJ: Arara Azul, 2007. 